\title{
AN ITERATIVE ALGORITHM FOR NONLINEAR FRACTIONAL-ORDER OSCILLATORS WITH MODIFIED RIEMANN-LIOUVILLE DERIVATIVE
}

\author{
Akuro Big-Alabo ${ }^{1}$ and Chinwuba Ossia ${ }^{1}$ \\ ${ }^{1}$ University of Port Harcourt
}

December 19, 2020

\begin{abstract}
This paper presents an iterative analytic algorithm for the approximate solution of nonlinear fractional-order oscillators. He fractional transform was applied to convert the fractional-order model, defined by a modified Riemann-Liouville derivative, to a model in continuous spacetime. Then, the approximate solution of the continuous model was applied to obtain an approximate solution for the fractional-order oscillator. The solution was obtained using the continuous piecewise linearization method (CPLM), which is a simple, accurate and efficient analytic algorithm. The applicability of the CPLM was demonstrated using representative examples in science and engineering and the maximum relative error of the approximate solution was found to be less than $0.2 \%$. This paper provides an analytical tool that can be applied in the study of fractional-order oscillations arising in various physical systems and technological processes.
\end{abstract}

\section{Hosted file}

Manuscript for MMAS_122020_Big-Alabo and Ossia.pdf available at https://authorea.com/ users/383794/articles/499631-an-iterative-algorithm-for-nonlinear-fractional-orderoscillators-with-modified-riemann-liouville-derivative

\section{Hosted file}

Figure 1.pdf available at https://authorea.com/users/383794/articles/499631-an-iterativealgorithm-for-nonlinear-fractional-order-oscillators-with-modified-riemann-liouvillederivative

\section{Hosted file}

Figure 2.pdf available at https://authorea.com/users/383794/articles/499631-an-iterativealgorithm-for-nonlinear-fractional-order-oscillators-with-modified-riemann-liouvillederivative

\section{Hosted file}

Figure 3.pdf available at https://authorea.com/users/383794/articles/499631-an-iterativealgorithm-for-nonlinear-fractional-order-oscillators-with-modified-riemann-liouvillederivative

\section{Hosted file}

Figure 4.pdf available at https://authorea.com/users/383794/articles/499631-an-iterativealgorithm-for-nonlinear-fractional-order-oscillators-with-modified-riemann-liouvillederivative 


\section{Hosted file}

Figure 5.pdf available at https://authorea.com/users/383794/articles/499631-an-iterativealgorithm-for-nonlinear-fractional-order-oscillators-with-modified-riemann-liouvillederivative

\section{Hosted file}

Figure 6.pdf available at https://authorea.com/users/383794/articles/499631-an-iterativealgorithm-for-nonlinear-fractional-order-oscillators-with-modified-riemann-liouvillederivative

\section{Hosted file}

Figure 7.pdf available at https://authorea.com/users/383794/articles/499631-an-iterativealgorithm-for-nonlinear-fractional-order-oscillators-with-modified-riemann-liouvillederivative

\section{Hosted file}

Figure 8.pdf available at https://authorea.com/users/383794/articles/499631-an-iterativealgorithm-for-nonlinear-fractional-order-oscillators-with-modified-riemann-liouvillederivative

\section{Hosted file}

Figure 9.pdf available at https://authorea.com/users/383794/articles/499631-an-iterativealgorithm-for-nonlinear-fractional-order-oscillators-with-modified-riemann-liouvillederivative

\section{Hosted file}

Figure 10.pdf available at https://authorea.com/users/383794/articles/499631-an-iterativealgorithm-for-nonlinear-fractional-order-oscillators-with-modified-riemann-liouvillederivative 